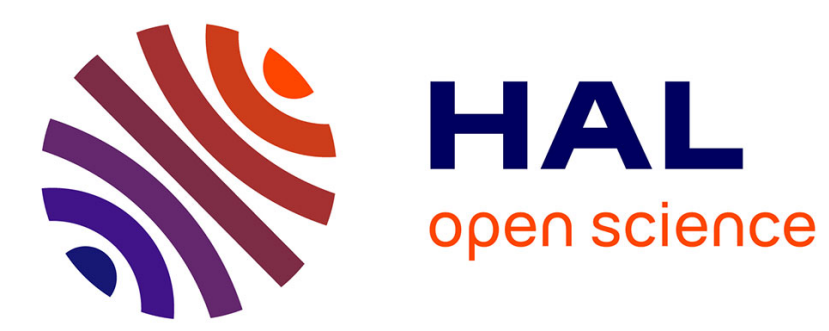

\title{
STRUCTURE AND EVOLUTION OF DIFFERENT ICE SURFACES AT LOW TEMPERATURE ADSORPTION STUDIES
}

\author{
B. Schmitt, J. Ocampo, J. Klinger
}

\section{- To cite this version:}

B. Schmitt, J. Ocampo, J. Klinger. STRUCTURE AND EVOLUTION OF DIFFERENT ICE SURFACES AT LOW TEMPERATURE ADSORPTION STUDIES. Journal de Physique Colloques, 1987, 48 (C1), pp.C1-519-C1-525. 10.1051/jphyscol:1987171 • jpa-00226317

\section{HAL Id: jpa-00226317 https://hal.science/jpa-00226317}

Submitted on 1 Jan 1987

HAL is a multi-disciplinary open access archive for the deposit and dissemination of scientific research documents, whether they are published or not. The documents may come from teaching and research institutions in France or abroad, or from public or private research centers.
L'archive ouverte pluridisciplinaire HAL, est destinée au dépôt et à la diffusion de documents scientifiques de niveau recherche, publiés ou non, émanant des établissements d'enseignement et de recherche français ou étrangers, des laboratoires publics ou privés. 
JOURNAL DE PHYSIQUE

Colloque $\mathrm{Cl}$, supplément au $\mathrm{n}^{\circ} 3$, Tome 48, mars 1987

\title{
STRUCTURE AND EVOLUTION OF DIFFERENT ICE SURFACES AT LOW TEMPERATURE ADSORPTION STUDIES
}

\author{
B. SCHMITT, J. OCAMPO and J. KIINGER \\ Laboratoire de Glaciologie et Géophysique de I'Environnement, \\ B.P. 96, F-38402 St-Martin-d'Hères Cedex, France
}

RESUME : Des mesures d'adsorption de $\mathrm{N}_{2}$ et Ar ont été faites à $77 \mathrm{~K}$ et $87 \mathrm{~K}$ sur différents types de poudres de glace. Un fort champ dipolaire est trouvé à la surface des glaces Ih broyées. Ce caractère polaire de la surface persiste après recuit à plus haute température malgré une importante diminution de la surface développée par les échantilions. Pour les glaces amorphes obtenues par condensation de vapeur d'eau à $77 \mathrm{~K}$ on a trouvé une structure très poreuse. Le mécanisme de base de leur formation semble être une agrégation de molécules $\mathrm{H}_{2} \mathrm{O}$ à laquelle s'ajoute des effets de recuit liés à la vitesse et à la température de condensation.

ABSTRACT : $\mathrm{N}_{2}$ and Ar adsorption measurements at $77 \mathrm{~K}$ and $87 \mathrm{~K}$ are done on different types of ice powders. A strong dipole field is found at the surface of crushed hexagonal ice and this polar nature persist after annealing at higher temperature, despite of a very large decrease in surface area. For amorphous ice obtained by vapour deposition at $77 \mathrm{~K}$, a very porous structure is found. The basic mechanism for its formation seems to be a randam aggregation of $\mathrm{H}_{2} \mathrm{O}$ molecules together with annealing effects depending on both condensation rate and temperature.

\section{INTRODUCTION}

The structure and dynamics of ice surfaces is the purpose of many studies, especially at temperatures near the melting point. In comparison at low and very low temperatures relatively little work is done.

However, in addition to fundamental relevances ices formed and stored at these temperatures are important for astrophysical problems such as evolution of cometary nuclei and molecule formation on icy interstellar grains.

For these purposes, fundamental studies are needed to determine the structure and dynamics of ices at low temperature in relation with their formation processes and the different kinds of evolution or alteration that they may have experienced.

Adsorption studies are generally considered to be a powerful approach for characterization of both surface and powder structures. Historically, Karasz and al [1] were the first to study $\mathrm{N}_{2}$ and $\mathrm{Ar}$ adsorption at $77 \mathrm{~K}$ on very thin films of ice. Since, several studies have been done for $\mathrm{N}_{2}$ adsorption on various ice powder samples [2 to 8]. The adsorption features of these different samples show great dependence on preparation conditions and thermal history : the total spread of the net BET heat of adsorption lies between 0.1 and $3.7 \mathrm{~kJ} / \mathrm{mol}$ with powders having surface areas from 0.1 to $400 \mathrm{~m}^{2} / \mathrm{g}$. On the other hand a single adsorption study has been done with Ar and $\infty$ gases at $77 \mathrm{~K}$ [8].

In the present study we first investigate gas-surface interactions and their evolutions for nitrogen and argon on freshly and annealed crushed Ih monocrystals. Secondly we start a systematic study of adsorption properties and structure of amorphous ice obtained by slow water vapour deposition at low temperature [9] . 


\section{EXPERTMENTAL PROCEDURES}

The first type of ice samples was obtained by crushing Ih monocrystals under vacuum $\left(10^{-6}\right.$ torr) in a stainless steel container at $77 \mathrm{k}$. Before the first measurement, the sample was always maintained at this temperature. The powders obtained with this method are very fine and without any sintering.

Amorphous snow samples were obtained by condensation of water vapor at $77 \mathrm{~K}$ under vacuum. Water vapor is obtained either from bubble free artificial monocrystals or deionized water (electrical resistivity : $18 \mathrm{~m} / \mathrm{cm}$ at $300 \mathrm{~K}$ ). This water was outgassed by several freeze-thaw cycles under pumping. The condensation took place directly from the glass vessel maintained at a desired temperature to the glass sample holder at liquid nitrogen temperature. The condensation rates used lie between $2.10^{-7}$ and $10^{-8}$ mol $\mathrm{cm}^{-2} \mathrm{~s}^{-1}$ and samples thickness varie from $50 \mu$ to $90 \mathrm{\mu l}$ with 7 hours deposition time.

In order to measure adsorption isotherms at $77 \mathrm{~K}$ on surfaces as $10 \mathrm{w}$ as $1 \mathrm{~m}^{2}$ we have improved an apparatus of volumetric type entirely immersed with its pressure gauge at the adsorption temperature. A second pressure gauge (Datametrics 590A) at room temperature allows us to calibrate each equilibrium pressure, read with the immersed gauge (Celesco P1A), with an accuracy of 0.02\% [9]. After non ideal gas corrections and dead space calibrations, an accuracy higher than $0.1 \mathrm{~m}^{2}$ is reached for surface area determination.

\section{RESULTS}

Freshly crushed hexagonal ice : Nitrogen and argon adsorption isotherms at $77 \mathrm{~K}$ on freshly crushed samples fit the BET equation in the 0.03 to 0.21 relative pressure range for $\mathrm{N}_{2}$ and in the 0.05 to 0.25 range for $\mathrm{Ar}$.

In table $\mathbf{I}$, we have summarized the following parameters : samples weight we, monolayer capacity $\mathrm{Vm}, \mathrm{BET}$ constant $\mathrm{C}$ and the net heat of adsorption $\Delta Q$ derived from $B E T$ theory. Specific surface area Sw measured with $N_{2}$ (Adsorbate cross section : $16.2 \AA^{2}$ at $77 \mathrm{~K})$ and $\operatorname{Vm}\left(\mathrm{N}_{2}\right) / \mathrm{Mm}(\mathrm{Ar})$ ratio are also listed.

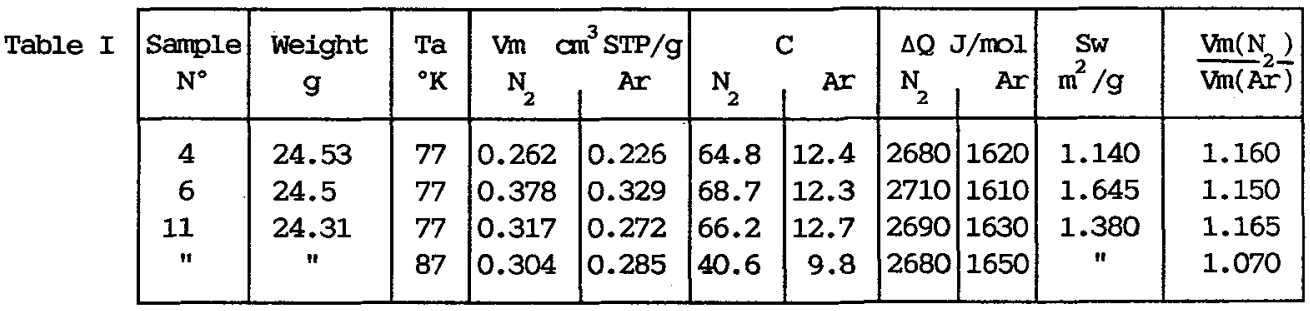

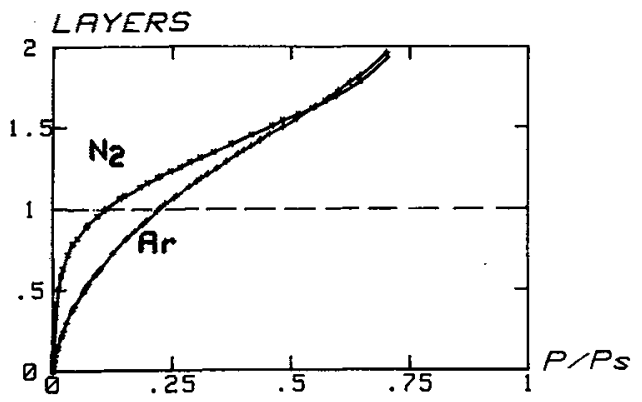

Figure 1: $N_{2}$ and Ar isotherms at $77 \mathrm{~K}$ on crushed Ih monocrystals 
We can see that the BET $C$ values are approximately the same for a given gas despite of differences of about $40 \%$ in specific surface areas. Moreover, the isotherms relative to $\mathrm{Vm}$ are virtually the same for $\mathrm{N}_{2}$ and $\mathrm{Ar}$ respectively (figure 1). These results indicate that ice-crushing at $77 \mathrm{~K}$ provides powders with good reproductibility of their adsorption properties. Conparisons between measurements at $77 \mathrm{~K}$ and $87 \mathrm{~K}$ show that nitrogen monolayer density has the same temperature dependence than liquid.

on the other hand, argon monolayer capacities have low values and an opposite temperature dependence. This leads to abnomally high $\mathrm{Vm}\left(\mathrm{N}_{2}\right) / \mathrm{Vm}(\mathrm{Ar})$ ratios.

Isosteric heats of adsorption $q_{s t}$ and differential molar entropies $\Delta S$ for $\mathrm{N}_{2}$ and Ar were measured for different surface coverages (figure 2). For argon, a steady decrease in isosteric heat takes place during the monolayer completion. A mean net heat of adsorption of $1650 \mathrm{~J} / \mathrm{mol}$ is calculated from the isosterics heats, this value is in good agreement with the BET one. The entropy of adsorbed argon molecules is slightly greater than that for the bulk liquid. A quite different behaviour is observed with nitrogen : the isosteric heat first slightly decreases until a coverage of about 0.8 monolayer is reached and then falls more abruptly to a very low value ( $\approx 800 \mathrm{~J} / \mathrm{mol}$ ).

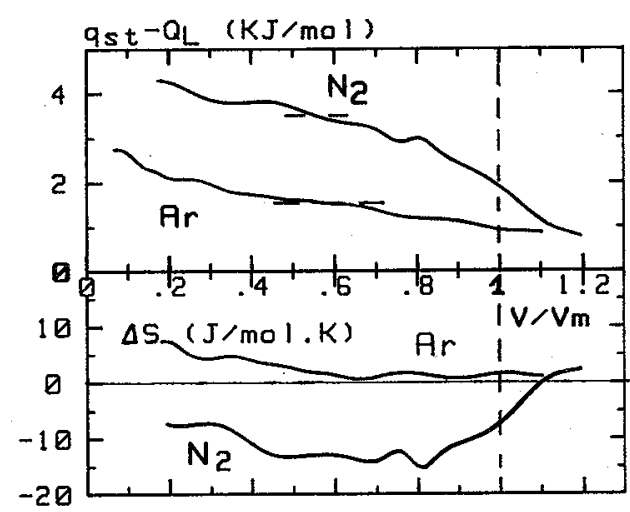

Figure 2: Net isosterics heats and differential molar entropies of adsorption (crushed Ih).

The corresponding entropies have large negative values and show an increase around the monolayer to the liquid bulk value. A mean value of $3500 \mathrm{~J} / \mathrm{mol}, 30$ g greater than the BET one, is decuced for the monolayer net heat of adsorption.

Aged crushed hexagonal ice : Freshly crushed ice showed great stability at 77K, no isotherm changes has been reconded at this temperature over more than 15 days. On the other hand, irreversible changes occured when the samples were annealed by bringing them to a temperature higher than $77 \mathrm{~K}$ for a desired time. After each annealing the samples were recooled to $77 \mathrm{~K}$ for adsorption measurement. For example, figure 3 shows successive adsorption isotherms for argon on a sample annealed at $213.2 \mathrm{~K}$. During the evolution, the monolayer capacity falls irreversibly while the relative isotherms, the $\mathrm{Vm}\left(\mathrm{N}_{2}\right) / \mathrm{Mm}(\mathrm{Ar})$ ratios and the net heats of adsorption remain unchanged, and this for annealing times as long as 2000 hours and temperatures between $190 \mathrm{~K}$ and $215 \mathrm{~K}$.

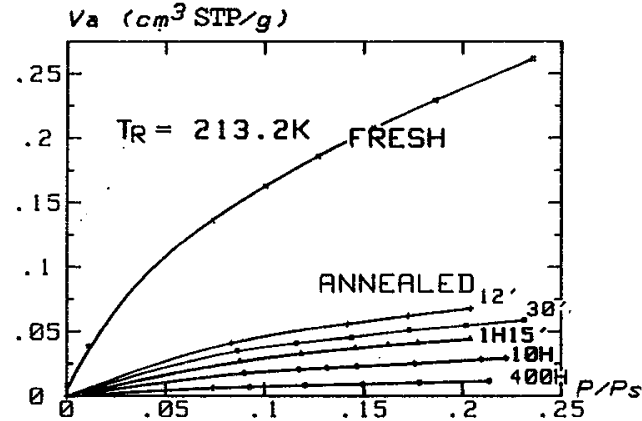

Figure 3: Ar isotherms on hexagonal ice freshly cruished and annealed at $213.2 \mathrm{~K}$ for different times.

Amorphous ice : Ice condensed at $77 \mathrm{~K}$ with a very $10 \mathrm{w}$ condensation rate is assumed to be amorphous [10]. As deposition proceeds, ice samples are transparent until a thickness of scme micrometers is reached, then they become progressively opaque and finally have the appearance of white powders.

These powdens have large nitrogen and argon adsorption capacities, but these capa- 
cities depend on condensation rates and in a different way for these two gases. Moreover, a slight decrease in these quantities is observed with time although" samples are maintained at $77 \mathrm{~K}$ between each adsorption measurement. This behaviour is even more pronounced at 87K. Therefore, a straightforward comparison between $\mathrm{N}_{2}$ and Ar monolayer capacity values is impossible, but we can estimate the $\mathrm{Vm}\left(\mathrm{N}_{2}\right) / \mathrm{Vm}(\mathrm{Ar})$ ratio from several successive isotherms.

In Table II, we have sumarized several features of amorphous condensates : sample weight, average thickness, condensation rate, $\mathrm{N}_{2}$ and Ar monolayer capacity, their average ratio and the apparent specific surface area calculated with $\mathrm{N}_{2}$.

Table II

\begin{tabular}{|c|c|c|c|c|c|c|c|}
\hline $\begin{array}{c}\text { Sample } \\
\mathrm{N}^{\circ}\end{array}$ & $\begin{array}{c}\text { Weight } \\
\mathrm{g}\end{array}$ & $\begin{array}{c}\text { Thickness } \\
\mu\end{array}$ & $\begin{array}{l}\text { Condensation } \\
\text { rate } \mathrm{mol} / \mathrm{cm}^{2} \mathrm{~s}\end{array}$ & $\begin{array}{c}\mathrm{Vn} \\
\mathrm{N}_{2}\end{array}$ & $\begin{array}{c}\mathrm{STP} / \mathrm{g} \\
\mathrm{Ar}\end{array}$ & $\begin{array}{l}\mathrm{Sw} \\
\mathrm{m}^{2} / \mathrm{g}\end{array}$ & $\frac{\operatorname{Vm}(N}{\operatorname{Vm}(A x)}$ \\
\hline 13 & 0.52 & 50 & $1.010^{-8}$ & 59.2 & 74.0 & 258 & 0.80 \\
\hline 12 & 5.13 & 500 & $1.010^{-7}$ & 26.4 & 31.4 & 115 & 0.84 \\
\hline 15 & 9.39 & 900 & $1.610^{-7}$ & 8.1 & 9.2 & 35 & 0.90 \\
\hline
\end{tabular}

Complete $\mathrm{N}_{2}$ adsorption-desorption isotherm has been made with sample $\mathrm{N}^{\circ} 15$ obtained with the highest condensation rate (Figure 4a). We can see a wide hysteresis 100p, with a sharp shoulder at low relative pressure, which indicates a wide pore size distribution, with a large quantity of very small pores. Pores size and volume distributions have been calculated in the range of validity of Kelvin equation (Radii > 18\&) using a numerical integration method [11] (figure 4b). For this calculation, crushed ice is taken as the non porous reference. For pores ranging between approximately 10 and $18 \AA$ (modified Kelvin equation range) we can only estimate their total volume with the drop of the desorption curve
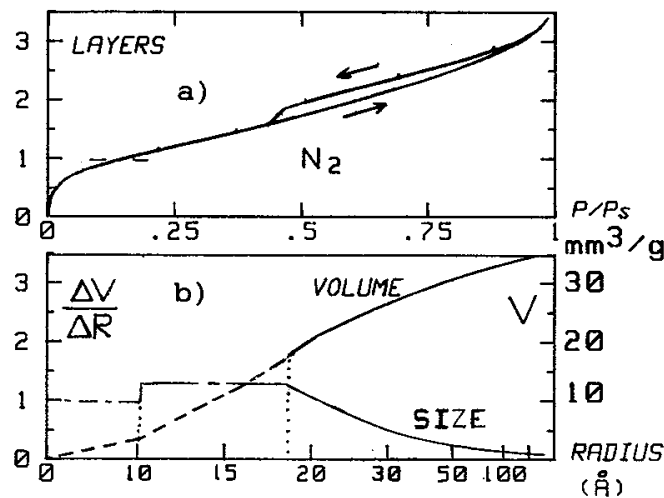

Figure 4: a) $\mathrm{N}_{2}$ adsorption and desorption isotherm, b) Pores size $(\Delta V / \Delta R)$ and volume (V) distribution of amorphous condensate. (condensation rate : $1.610^{-7} \mathrm{~mol} / \mathrm{cm}^{2} \mathrm{~s}$ ). around the shoulder at $P / P S=0.42$.

Moreover, an estimation of the micropores volume (Radii < $10 \AA$ ) is obtained with Dubinin-Raduskevitch plot corrected from adsorption in larger pores [12] .

For this sample we find that pores with radii less than $18 \AA$ account for approximately $40 \%$ of the pore volume, that is to say $0.017 \mathrm{~cm}^{3} / \mathrm{g}$.

Preliminary results for amorphous ice obtained with lower condensation rates show that a smaller water vapour flow increases largely the monolayer capacity Vm but decreases appreciably the Vm ratio (table II). Moreover, the corresponding isotherms are more flat at high pressures. These behaviours are obvious in figure 5 (A crushed Ih ice sample is also shown for comparison). Adsorption measurements have also been done on these condensates after annealing at $190 \mathrm{~K}$ for 10 minutes. 


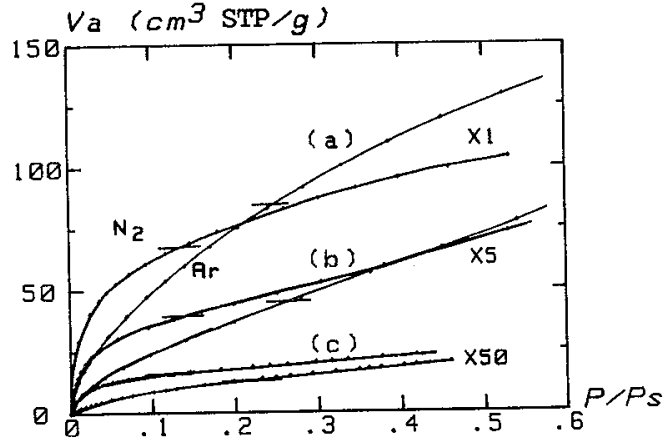

Figure 5: $\mathrm{N}_{2}$ and Ar isotherms at $77 \mathrm{~K}$ on amorphous condensates (a: ech 13), (b: ech 15) and on hexagonal ice (c).

A very low final adsorption capacity corresponding to a value of less than $0.1 \mathrm{~m}^{2} / \mathrm{g}$ is measured. In addition, we have observed that large quantities of gases are occluded when annealing is done with preadsorbed gases $\left(\mathrm{N}_{2}\right.$ or $\left.\mathrm{Ar}\right)$.

\section{DISCUSSION}

The abnormally high $\operatorname{Vm}\left(\mathrm{N}_{2}\right) / \mathrm{Vm}(\mathrm{Ar})$ ratio observed with crushed Ih ice cannot be explained with $\mathrm{N}_{2}$ and Ar theoretical cross sections calculated from bulk liguid or solid. With an adsorbate cross section of $16.2 \AA^{2}$ for $\mathrm{N}_{2}$ a value of $18.8 \AA^{2}$ is calculated for argon at $77 \mathrm{~K}$. The argon monolayer is then $30 \%^{2}$ less dense than the liquid. Several authors have already observed $\mathrm{Vm}$ ratios greater than unity, this high value going generally with a low argon BET constant [13]. Indeed when, as in our case for argon, the adsorption heat is sufficiently low, the adsorbate lateral mobility on the surface will tend to disrupt any tendency for an organized structure to develop and the adsorbed layer may appear more as a two dimensional gas [14].

The positive entropy of adsorbed argon molecules confims their greater mobility relative to liquid state. The increase in monolayer capacity with rising temperature can then be explained in term of adsorbed film compressibility because the pressure needed to build the argon "statistical monolayer" is four times greater at $87 \mathrm{~K}$ than at $77 \mathrm{~K}$.

For nitrogen, its increased adsorption energy compared to argon can be explained if a high interaction between the quadrupole moment of nitrogen molecules and a dipole field at the surface of ice is considered. The quite negative entropy of nitrogen molecules in the first monolayer agree with this concept of oriented adsorption on a polar surface. This polar nature of the surface of crushed ice persists after annealing at higher temperature. Then the evolution process responsible for the decrease in surface area and the sintering of ice particles observed with time don't seem to influence on the surface structure.

The adsorption properties of amorphous ice obtained by vapour deposition at low temperature are characteristic of a porous structure with wide pore size distribution. The larger adsorption capacities and the more pronounced type I isotherms observed with the sample prepared at lowest condensation rate suggest that a narrower porosity develops when more isothermal conditions are used. Moreover, the low value of the $\mathrm{Vm}\left(\mathrm{N}_{2}\right) / \mathrm{Mn}(\mathrm{Ar})$ ratio is a further argument for the presence of large quantities of pores only a few molecular diameters wide. Indeed, the increased adsorption energy in micropores causes the condensation of argon in these very thin volumes (with probably solid density) while an angon monolayer is approximately $40 \%$ 
less dense on a free surface. This "monolayer ratio" is then linked with the micropore ratio.

These properties of amorphous ice can be explained if a random aggregation mechanism is considered for the condensation of $\mathrm{H}_{2} \mathrm{O}$ molecules at low temperatures. The structures obtained by this way are extremely porous with continuous pore size distribution $[15,16]$, but are also very unstable. With our deposition conditions we must added annealing effects due to the thermal energy of molecules at $77 \mathrm{~K}$ and the latent heat released during condensation (spot heating). The slight evolution observed after condensation show that a slow molecular rearrangement occurs even at this temperature, this great unstability of ice condensed at low temperature is at the origin of the large gas occlusion when samples were warmed at somewhat higher temperature.

\section{CONCLUSION}

Comparisons between adsorption behaviour of nitrogen and argon on both crushed Ih ice and condensed amorphous ice are shown to provide useful informations about the structure and the nature of their surfaces.

The polar nature observed for ice surfaces crushed at $77 \mathrm{~K}$ must be compared to the only slightly polar surfaces observed by Adamson et al for two types of condensed ice $[2,8]$. This difference is probably linked with their different formation processes.

on the other hand, we have found that the main feature of amorphous ice condensates is a large porosity and that both temperature and condensation rate seem to be the first parameters determining its porasity and stability.

For astrophysical topics such as synthesis of hydrogen molecules on icy interstellar grains the presence of pores in which an increase in adsorption occurs at very low pressure is of particular importance. For this, a study of the ponous structure of mixed ice condensates, and more particularly the micropore volume, is needed for temperatures below 20K. If the condensation mechanism of amorphous ices is a molecular aggregation process, then the very low temperatures and extremely low gas densities prevailing in space are ideal conditions for the formation of icy grains with large quantities of very narrow pores.

Some few results in cryopumping techniques litterature seem to prove that large quantities of hydrogen molecules are still adsorbed at temperatures near $20 \mathrm{~K}$ on different kinds of ices $\left(\mathrm{H}_{2} \mathrm{O}, \mathrm{CO}_{2}, \mathrm{CH}_{4}, \ldots\right)$ condensed at this temperature $[17,18]$. In addition, the evolution properties of amorphous icy condensates are probably the key of several processes such as gas occlusion, phase change, etc..., occurring when these aggregates are warmed. The composition and evolution of cometary matter will then strongly depend on the themal history of ices before comet formation [19].

Acknowledgements : Financial support from the french INSTITUT DES SCIENCES DE L'UNIVERS grant ATP "Planétologie" $N^{\circ}$ 57-24 is gratefully acknowledged.

\section{References}

[1] Karasz F.E., Charpion W.M.and Halsey G.D. J.Phys.Chem. 60, (1956) 376-378

[2] Adamson A.W., Dormant L.M. and Orem M. J.Coll.Interface Sci. 25, (1967) 206-217

[3] Chormley J.A., J.Chem.Phys. 46, (1967) 1321-1325 and 48, (1968) 503-508

[4] Jellinek H.H.G. and Ibrahim S.H. J.Coll. Interface Sci. 25, (1967) 245-254

[5] Ocampo J. and Klinger J. J.Coll. Interface Sci. 86, (1982) 377-383

[6] Ocampo J. and Ilinger J. J.Phys.Chem. 87, (1983) 4167-4170 
[7] Mayer E. and Pletzer R. Nature 319, (1986) 298-301

[8] Nair N.K. and Adamson A.W. J.Phys. Chem. 74, (1970) 2229-2230

[9] Schmitt B. (1986) "La surface de la glace: structure, dynamique et interactions. Inplications astrophysiques" Thesis, U.S.T.M.G. Grenoble, France.

[10] Olander D.S. and Rice S.A. Proc.Nat.Acad.Sci.U.S.A. 69, (1972) 98-100

[11] Pierce C. J.Phys.Chem. 57, (1953) 149-157

[12] Gregg S.J. and Sing K.S.W., "Adsorption, Surface Area and Porosity" (Academic Press, New York, 1982)

[13] Rouquerol F. (1965) Thesis, Faculté des Sciences Paris, France

[14] Lowell S., Introduction to powder surface area (Whiley-Interscience Publ. 1979)

[15] Meakin P. J.Coll. Interface Sci. 96, (1983) 415-423

[16] Pfeifer P. and Avnir D. J.Chem. Phys. 79, (1983) 3558-3565

[17] Yuferov V.B. and Busol F.I. Soviet Phys. -Tech.Phys. 11, (1967) 1518-1524

[18] Yuferov V.B. and Kobzev P.M. Soviet Phys.-Tech.Phys. 14, (1970) 1261-1265

[19] Ocampo J., Schmitt B. and Klinger J. (1986) ESA Proceedings (to be published)

\section{COMMENTS}

remark of J. DORE

The large volume of this material would make it ideal for study by small-angle scattering techniques with neutrons (SANS) or X-rays (SAXS). There is much interest in the characterization of porous networks in terms of a fractal representation.

The SAS measurements would yield the fractal dimensionality and the way this varied with deposition conditions would provide valuat?e information on the way the molecules are laid down and build the surface structure.

Answer :

It would certainly be very interesting to do SAXS or SANS experiments on this type of amorphous ice in order to confirm our results. But these scattering techniques are also limited to minimal size of around $15 \&$ for pore size distribution determinations. On the other hand, the shape of the pores may probably be obtained with these experiments. The fractal dimentionality can easily be derived from the pores volume distribution. The relationship between this fractal dimension and the basic mechanisms of condensation are fairly well understood but when annealing effects occur in the same time, the problem is more complicated and it is necessary to perform computer simulation for explaining the detailed structure of these condensates. 